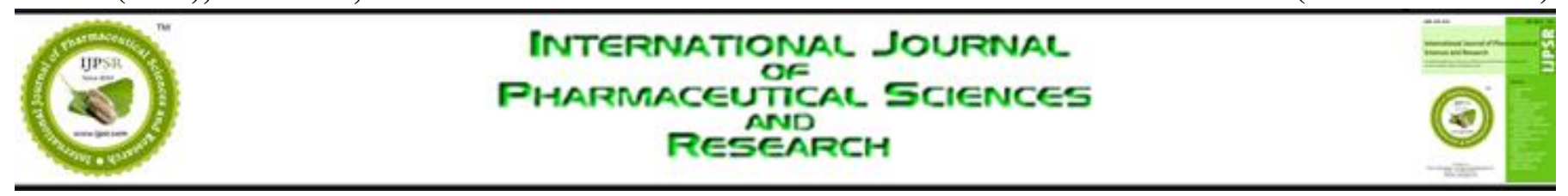

Received on 08 March 2014; received in revised form, 20 May 2014; accepted, 26 June 2014; published 01 September 2014

\title{
THE EFFECT OF VALERIAN ON THE PHARMACOKINETICS OF CARBAMAZEPINE IN HEALTHY RABBITS
}

Issam Abushammala

Department of Pharmaceutics and Industrial Pharmacy, College of Pharmacy, Al-Azhar University-Gaza, 1277, Palestine.

Keywords:

Carbamazepine, Valerian, Pharmacokinetic, Interaction

\section{Correspondence to Author:}

Issam Abushammala

Department of Pharmaceutics and Industrial Pharmacy, College of Pharmacy, Al-Azhar University-Gaza, 1277, Palestine.

E-mail: issam.abushammala@uv.es

\begin{abstract}
This article aimed to evaluate the effect of valerian on a single dose kinetic of carbamazepine in rabbits. Five healthy male rabbits in a randomized, two-crossover design were enrolled in this study. Rabbits were divided into two groups; the first received a single dose of $100 \mathrm{mg}$ carbamazepine (CBZ) suspension. The second group received CBZ $100 \mathrm{mg}$ suspension concurrently with valerian (VAL) $25 \mathrm{mg}$ dry extract. After a washout period of one week, the doses were given in a reverse manner. Blood samples were collected over 24 hours. Serum was assayed for CBZ using chemiluminescent enzyme immunoassay (CLEIA). Pharmacokinetic (PK) parameters were determined for CBZ in both cases using noncompartmental analysis. Statistically insignificant differences $P \geq 0.05$ were found in PK parameters when CBZ was given alone or concurrently with VAL; the values were $\mathrm{C}_{\max } 6.52 \pm 1.6 \mu \mathrm{g} / \mathrm{ml}$ versus $5.32 \pm 1.4 \mu \mathrm{g} / \mathrm{ml}, \mathrm{t}_{\max }$ $2.6 \pm 0.9 \mathrm{~h}$ versus $3.3 \pm 0.9 \mathrm{~h}, \mathrm{AUC}_{0-24} 83.80 \pm 28.8 \mu \mathrm{g} \cdot \mathrm{h} / \mathrm{ml}$ versus $60.4 \pm$ $12 \mu \mathrm{g} \cdot \mathrm{h} / \mathrm{ml}, \mathrm{AUC}_{0-\infty} 166.20 \pm 74 \mu \mathrm{g} \cdot \mathrm{h} / \mathrm{ml}$ versus $104.75 \pm 12 \mu \mathrm{g} \cdot \mathrm{h} / \mathrm{ml}, \mathrm{k}_{\mathrm{e}}$ $0.033 \pm 0.006 \mathrm{~h}^{-1}$ versus $0.038 \pm 0.012 \mathrm{~h}^{-1}$ and $\mathrm{t}_{1 / 2} 21.81 \pm 3.96 \mathrm{~h}$ versus 20.71 $\pm 10.09 \mathrm{~h}$ respectively. The result of the study demonstrated that valerian does not affect PK of CBZ, there are no cautions, regarding to dose or administration pattern of $\mathrm{CBZ}$ with valerian should be taken.
\end{abstract}

INTRODUCTION: Carbamazepine (CBZ) is one of the commonly used conventional antiepileptic drugs. CBZ has a considerable low therapeutic index and a wide inter-individual variation at tolerable doses which make therapeutic drug monitoring necessary ${ }^{1,2}$. Also, CBZ is a potent enzyme inducer and is a subject to auto-induction. Those properties make CBZ prone to interactions with the co-administered drug, herbal products, and food.

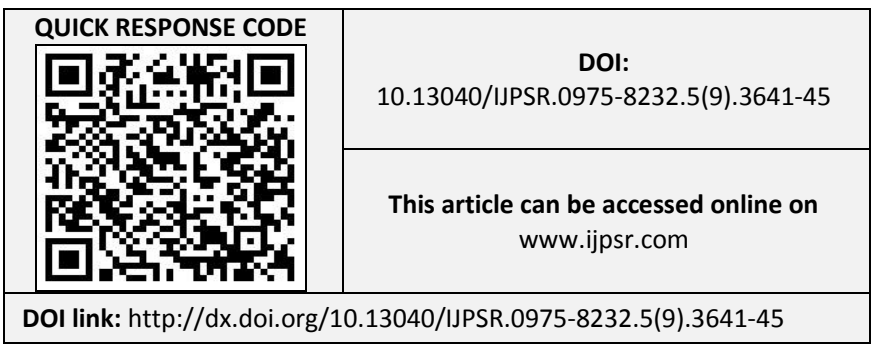

Drug interactions are classified into pharmacodynamic and pharmacokinetic types ${ }^{3-5}$. The variability in drug pharmacokinetic is responsible for the lack of a consistent relationship between dose given of the drug and its concentration at the site of action ${ }^{6}$. Herb-drug interactions are mostly pharmacokinetic. Fluctuations in the bioavailability of drug and herb molecules in the body can result from changes in absorption, distribution, metabolism, and elimination. Induction or inhibition of hepatic and intestinal drug-metabolizing enzymes, e.g. CYP450 and drug transporters such as P-glycoprotein were suggested as possible mechanisms ${ }^{7,8}$.

The consumption of herbal products for a variety of health-related problems has steadily increased over the past few years ${ }^{9,10}$. 
Valerian (VAL) is a popular herbal product often used to treat insomnia and anxiety. It is the most common non-prescription sedative used in Europe 11, 12. CBZ-herb interactions were an interesting and important issue for many researchers ${ }^{13}$. Possible pharmacokinetic VAL-CBZ interactions are still uninvestigated. The present study aims to examine the effect of VAL on PK of CBZ in healthy rabbits.

\section{MATERIALS AND METHODS:}

Animals: Five healthy male rabbits (weight: $3.26 \pm$ $0.11 \mathrm{Kg}$, age: $7-9$ months were enrolled in the study. The rabbits were obtained from Asdda for animal production and welfare center, where follow up care and clinical examination was performed, and rabbits' health state was certified (khanunis, Palestine). Rabbits fasted for 12 hours with free access to water by ad libitum before the beginning of the study. The study was carried out at Al-Azhar University-Gaza, College of Pharmacy, Gaza, Palestine. The study was approved by the institutional ethics committee and was conducted under the supervision of a veterinary physician.

Study Design: A single dose, two-crossover design study was conducted in rabbits. The rabbits were divided into two groups. The first one received a volume equivalent to $100 \mathrm{mg} \mathrm{CBZ}$ from an oral suspension 2\% (Tegretol, Novartis), whereas the second group received the same volume of CBZ suspension in combination with a volume of prepared in laboratory suspension equivalent to 25 $\mathrm{mg}$ valerian dry extract. It was prepared by pulverizing five tablets of commercial valerian film-coated tablets (Relaxing, Laboratoires Pharmaceutiques Trenker). Each tablet contains $500 \mathrm{mg}$ of dry valerian extract. Weight of the powder equivalent to $0.5 \mathrm{~g}$ VAL dry extract was suspended in $20 \mathrm{ml}$ distilled water. After one week the second group received CBZ suspension alone and the first received $\mathrm{CBZ}$ suspension in combination with VAL to complete the cross-over design. Carbamazepine oral suspension and valerian tablets were purchased from a local pharmacy (Gaza, Palestine). The dose was given orally by gavage to each rabbit. It was put in the corner of the mouth and the suspension was pushed down slowly, to avoid choking. General clinical safety was assessed by physical examination during the study, washout period and at the end of the study.
Blood Sampling: Rabbits were placed in rabbit restraining box device. The marginal ear vein was located, and the hair was removed. Gentle stroking and tapping of the ear may make the vein more visible. Local anesthetic was applied to prevent the jerking of the rabbit as a result of venipuncture 15 minutes before starting the study. Inserting a small needle (23 gauge) butterfly attached to a syringe in the marginal ear vein ${ }^{14}$. Serial venous blood samples were collected (ca $0.7 \mathrm{ml}$ ) in vacutainer tubes according to the time schedule $0.0,0.5,1.0$, $1.5,2.0,2.5,3.0,4.0,5.0,6.0$ and $24.0 \mathrm{~h}$ after receiving the dose. Blood samples were centrifuged at 3,000 rpm for 5 minutes, and serum was transferred into clean plastic tubes. Serum samples (ca. $200 \mu \mathrm{l}$ ) were kept in the refrigerator until being analyzed within $24 \mathrm{~h}$.

Analysis of Serum Samples: The analysis was performed by Carbamazepine kit based on chemiluminescent enzyme immunoassay (CLEIA) and Immulite 1000 immunoassay system (Siemens Healthcare Diagnostics).

Pharmacokinetic Analysis: The plasma pharmacokinetic parameters were estimated, which included the observed maximum plasma concentration $\mathrm{C}_{\max }$, the time to reach $\mathrm{C}_{\max },\left(\mathrm{T}_{\max }\right)$ and the area under the plasma concentration-time curve from 0 hours to last measurable concentration $\left(\mathrm{AUC}_{0-\mathrm{t}}\right)$ and 0 hours to infinity $\left(\mathrm{AUC}_{0-\infty}\right)$. The $\mathrm{C}_{\max }$ and $\mathrm{T}_{\max }$ were directly determined from the serum concentration versus time curves. The Area under the curve from 0 hours to $\mathrm{t}\left(\mathrm{AUC}_{0-\mathrm{t}}\right)$ was calculated by the linear trapezoidal rule. The area under the curve from 0 hours to infinity $\left(\mathrm{AUC}_{0-\infty}\right)$ was estimated by summing the area from $\mathrm{AUC}_{0-\mathrm{t}}$ and $\mathrm{AUC}_{0-\infty}$, where $\mathrm{AUC}_{0-\infty}=\mathrm{AUC}_{0-\mathrm{t}}+\mathrm{C}_{\mathrm{t}} / \mathrm{k}_{\mathrm{e}}$, with ' $\mathrm{C}_{\mathrm{t}}$ ' defined as the last measured serum concentration at time $\mathrm{t}$, and $\mathrm{k}_{\mathrm{e}}$ is the elimination rate constant. The elimination rate constant $\mathrm{k}_{\mathrm{e}}$ was estimated by the least squares regression of plasma concentration-time data points lying in the terminal region by using semilogaritmic dependence that corresponds to first-order kinetics. The half-life $t_{1 / 2}$ was calculated as $0.693 / \mathrm{k}_{\mathrm{e}}$. Pharmacokinetic analysis was performed using model-independent method (NonCompartmental Approach) WinNonlin Professional Software (Version 6.3, Pharsight Corporation, Cary, NC). 
Statistical Analysis: Analysis of Variance (ANOVA) was used to compare the calculated pharmacokinetic parameters of CBZ alone or with VAL, using general linear model procedures, in which sources of variation were subject and period. The statistical analysis was performed using SPSS, version 16. A statistically significant difference was considered when $\mathrm{P} \leq 0.05$.

RESULTS AND DISCUSSION: Carbamazepine (CBZ) is a first-line antiepileptic drug which may be prone to drug interactions. Serious herbcarbamazepine interactions with clinical evidence were reported. The majority were pharmacokineticbased $^{13}$.

In this study, the effect of VAL on PK of CBZ was investigated using rabbits. The mean plasma concentrations of CBZ when administered alone or in combination with VAL are shown in Fig. 1.

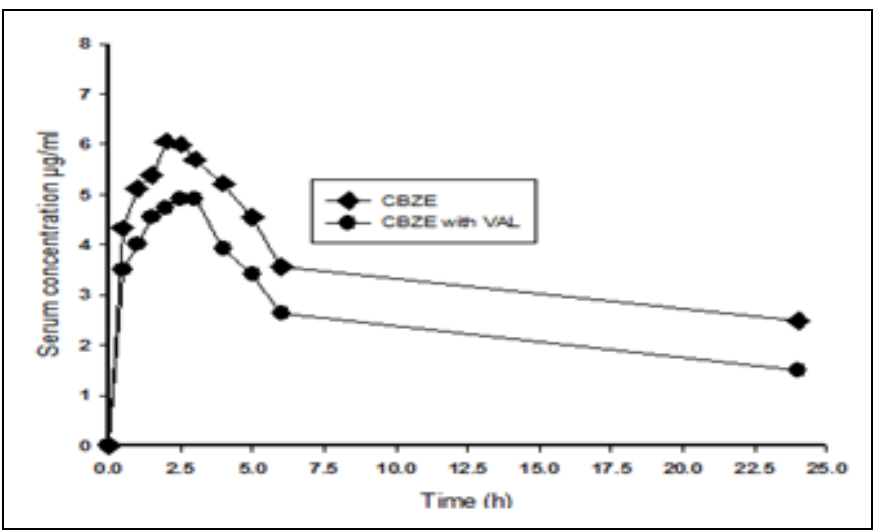

FIG. 1: THE MEAN RABBIT SERUM CONCENTRATION-TIME PROFILE OF CBZ WHEN ADMINISTERED ALONE AND IN COMBINATION WITH VAL $(\mathbf{n}=5)$

The concentration-time profile in both cases indicated that they were comparable. The mean $\mathrm{C}_{\max }$ was $6.52 \pm 1.6 \mu \mathrm{g} / \mathrm{ml}$ versus $5.32 \pm 1.4$ $\mu \mathrm{g} / \mathrm{ml}$, and $\mathrm{t}_{\max }$ was $2.6 \pm 0.9 \mathrm{~h}$ versus $3.3 \pm 0.9 \mathrm{~h}$, of CBZ after alone and concomitant administration of CBZ with VAL, respectively Table 1. VAL has not changed the absorption phase of CBZ. Some herbal products increased absorption of poor watersoluble CBZ - through enhancement of dissolution or altering gastric emptying rate ${ }^{15,16}$. Psyllium, septilin, and soya bean decreased bioavailability and plasma level of CBZ by affecting its gastric absorption $^{17-19}$.

By comparing the rest PK parameters, statistically insignificant differences were found in Table 1. The elimination of CBZ was not affected by VAL; $\mathrm{K}_{\mathrm{e}}$ and $\mathrm{t}_{1 / 2}$ were not changed when VAL was coadministered significantly. CYP3A4 is the most important enzyme involved in the metabolism of CBZ as it leads to the formation of the active metabolite CBZ 10,11-epoxide, which appears to contribute to the toxicity and efficacy of CBZ ${ }^{20,21}$. CYP3A6 is responsible for CBZ metabolism in the rabbit $^{22}$. The rabbit CYP3A6 and human CYP3A4 isoform have similar $\mathrm{p}-450$ predominance, and substrate specificity, and both are induced by rifampicin ${ }^{23}$.

CYP3A4 is the most important isoform of CYP450 in critical tissues, such as hepatic and gastrointestinal tract. This enzyme is involved in the biotransformation of over $70 \%$ of the drugs in use today; hence, the possible risk of adverse events due to alterations in this pathway is high ${ }^{7}$.

Some herbal products induced CYP3A4 and diminished CBZ plasma level, e.g. Ginko biloba ${ }^{24}$ and soybean ${ }^{19}$. Others like grapefruit juice and Polygonum cuspidatum inhibited CYP3A4 led to an elevated plasma level of $\mathrm{CBZ}^{25,26}$.

TABLE 1: SUMMARY OF MEAN PHARMACOKINETIC PARAMETERS OF CBZ 100 MG WITH AND WITHOUT VAL 25 MG (n=5)

\begin{tabular}{cccc}
\hline Pharmacokinetic parameter $^{\mathbf{a}}$ & $\begin{array}{c}\text { CBZ alone } \\
\text { Mean } \pm \text { SD }^{\mathbf{b}}\end{array}$ & $\begin{array}{c}\text { CBZ and VAL } \\
\text { Mean } \pm \text { SD }^{\mathbf{b}}\end{array}$ & p-Value $^{\mathbf{c}}$ \\
\hline $\mathrm{C}_{\max }(\mu \mathrm{g} / \mathrm{ml})$ & $6.52 \pm 1.66$ & $5.320 \pm 1.386$ & 0.355 \\
$\mathrm{~T}_{\max }(\mathrm{h})$ & $2.60 \pm 0.96$ & $3.300 \pm 0.975$ & 0.404 \\
$\mathrm{AUC}_{0-24}(\mu \mathrm{g} \cdot \mathrm{h} / \mathrm{ml})$ & $83.80 \pm 28.80$ & $60.43 \pm 12.08$ & 0.833 \\
$\mathrm{AUC}_{0-\infty}(\mu \mathrm{g} \cdot \mathrm{h} / \mathrm{ml})$ & $166.20 \pm 74.50$ & $104.75 \pm 12.08$ & 0.420 \\
$\mathrm{t}_{1 / 2}(\mathrm{~h})$ & $21.81 \pm 3.96$ & $20.71 \pm 10.09$ & 0.202 \\
$\mathrm{~K}_{\mathrm{e}}\left(\mathrm{h}^{-1}\right)$ & $0.0326 \pm 0.0058$ & $0.0381 \pm 0.0124$ & 0.161 \\
\hline
\end{tabular}

a: Abbreviations are $\mathrm{C}_{\max }$ : Maximum serum concentration, $\mathrm{T}_{\max }$ : Time to $\mathrm{C}_{\max }, \mathrm{AUC}_{0-24}$ : Area under the curve from $0 \mathrm{~h}$ to $24 \mathrm{~h}$, $\mathrm{AUC}_{0-\infty}$ : Area under the curve from $0 \mathrm{~h}$ to infinity, $\mathrm{t}_{1 / 2}$ : Terminal half-life and $\mathrm{K}_{\mathrm{e}}$ : Terminal elimination constant, ${ }^{\mathrm{b}}:$ SD: Standard deviation, ${ }^{c}$ : Statistical significance $\mathrm{p} \leq 0.05$. 
Extracts from the valerian root have been shown to inhibit CYP3A4 activity in vitro ${ }^{27-29}$. The effects of valerian on co-administered medications in vivo appear to be less significant than those observed in vitro. Studies designed to probe in-vivo drug interactions between valerian and substrates for CYP3A4 or CYP2D6 have come back negative. Minimal effects on CYP3A4 activity and no effect on CYP2D6 activity were reported following 14 days of valerian administration (1 gram/day) ${ }^{30}$. Similar results were found in volunteers for a variety of probe substrate relating to CYP450 3A4, 1A2, 2E1, and 2D6 following administration of valerian for a month. The results showed that valerian is unlikely to cause pharmacokinetic interaction mediated by major CYP450 enzymes ${ }^{31}$.

The absorption and elimination phases of CBZ were not affected by co-administration of VAL; therefore, the bioavailability; area under the curve AUC, of CBZ was not changed significantly by VAL. Changes in the bioavailability of CBZ were reported with unknown mechanisms ${ }^{13}$. The utility of animals to study drug-herb interactions is well documented 7, 32. Pharmacokinetic of a drug showed not be modified by repeated blood withdrawal from the same rabbit ${ }^{33}$. All five rabbits had completed the study, and there were no death or replacement during the study. Clinical physical examination during and post-study indicated no abnormalities. The present study showed good tolerability at the given doses for CBZ and VAL.

CONCLUSION: Despite the widespread of herbal medicines documented herb-drug interactions are few. The result of the study indicated that valerian had not altered PK parameters of CBZ in rabbits. CBZ can be used safely with VAL preparations.

ACKNOWLEDGMENT: The author would like to thank Mr. Mohammed Abuaffash, the director of Medical Relief Society-Gaza for providing the analysis facility and for Dr. Ali Abuzaid for his consultation about statistical analysis.

\section{CONFLICT OF INTEREST: Nil}

\section{REFERENCES:}

1. Anderson GD: Pharmacokinetic, pharmacodynamic, and targeted pharmacogenetic therapy of antiepileptic drugs. Therapeutic Drug Monitoring 2008; 30: 173-80.
2. Eadie MJ: Therapeutic drug monitoring antiepileptic drugs. British Journal of Clinical Pharmacology 1998; 46: 185-93.

3. Patsalos PN, Froscher W, Pisani F and van Rijn CM: The importance of drug interactions in epilepsy therapy. Epilepsia 2002; 43: 365-85.

4. Ioannides C: Pharmacokinetic interactions between herbal remedies and medicinal drugs. Xenobiotica 2002; 32: 451478.

5. Zhou SF, Gao YH, Wen Q J, Huang M, Xu AL and Paxton JW: Interactions of herbs with cytochrome P450. Drug Metabolism Reviews 2003; 35: 35-98.

6. Park PW, Seo YH, Ahn JY, Kim KA and Park JY: Effect of CYP3A5*3 genotype on serum carbamazepine concentrations at steady state in Korean epileptic patients. Journal of Clinical Pharmacy and Therapeutics 2009; 34: 569-574.

7. Stargrove MB, Treasure $\mathrm{J}$ and McKee DL: Herb, nutrient, and drug Interactions: Clinical implications and therapeutic strategies. Elsevier Health Sciences, first edition 2008.

8. Hu Z, Yang X, Ho PC, Chan SY, Heng PW, Chan E, Duan W, Koh HL and Zhou S: Herb-drug interactions: a literature review. Drugs 2005; 65:1239-82.

9. Fong $\mathrm{HH}$ : Integration of herbal medicine into modern medical practices: Issues and prospects. Integrated Cancer Therapy 2002; 1: 287-93.

10. Foster S and Tyler V: Tyler's Honest Herbal: A Sensible Guide to the Use of Herbs and Related Remedies. Routledge, fourth edition 1999.

11. Houghton PJ: The scientific basis for the reputed activity of valerian. Journal of Pharmacy and Pharmacology 1999; 51: 505-512.

12. Krystal $\mathrm{AD}$ and Ressler $\mathrm{I}$ : The use of valerian in neuropsychiatry. CNS Spectrums 2001; 6: 841-47.

13. Fong SYK, Gao $Q$ and Zuo Z: Interaction of carbamazepine with herbs, dietary supplements, and food: A systematic review. Evidence-Based Complementary and Alternative Medicine 2013; 2013: 15, article ID: 898261.

14. Chow SC and Liu JP: Design and analysis of bioavailability and bioequivalence studies. Chapman and Hall/CRC Press, third edition 2008.

15. Liu P and Wei L: Effect of Platycodon grandiflorum on the blood concentration of carbamazepine in rabbits. Evaluation and Analysis of Drug-Use in Hospitals of China 2008; 8: 366-69.

16. Sidhu S, Malhotra S and Garg SK: Influence of high-fat diet (butter) on the pharmacokinetics of phenytoin and carbamazepine. Methods and Findings in Experimental and Clinical Pharmacology 2004; 26: 635-38.

17. Etman MA: Effect of a bulk-forming laxative on the bioavailability of carbamazepine in man. Drug Development and Industrial Pharmacy 1995; 21: 1901-06.

18. Garg SK, Islam AS and Kumar N: Effect of septilin-a herbal preparation on the pharmacokinetics of carbamazepine in rabbits. Indian Journal of Physiology and Pharmacology 1998; 42: 527-32.

19. Singh D and Asad M: Effect of soybean administration on the pharmacokinetics of carbamazepine and omeprazole in rats. Fundamental and Clinical Pharmacology 2010; 24: 351-55.

20. Potter JM and Donnelly A: Carbamazepine-10,11-epoxide in therapeutic drug monitoring. Therapeutic Drug Monitoring 1998; 20: 652-57.

21. So EL, Ruggles KH, Cascino GD, Ahmann PA and Weatherford KW: Seizure exacerbation and status 
epilepticus related to carbamazepine-10,11-epoxide. Annals of Neurology 1994; 35: 743-46.

22. Mesdjian E, Sérée E, Charvet B, Mirrione A, BourgarelRey V, Desobry A and Barra Y: Metabolism of carbamazepine by CYP3A6: a model for in vitro drug interactions studies. Life Science 1999; 64: 827-35.

23. Weber A, Kaplan M, Chughtai SA, Cohn LA, Smith AL and Unadkat JD: CYP3A inductive potential of the rifamycins, rifabutin and rifampin, in the rabbit. Biopharmaceutics \& drug disposition 2001; 22: 157-68.

24. Chandra RH, Rajkumar $M$ and Veeresham $C$ : Pharmacokinetic interaction of Ginkgo biloba with carbamazepine. Planta Medica 2009; 75: 107.

25. Chi YC, Lin SP and Hou YC: A new herb-drug interaction of Polygonum cuspidatum, a resveratrol-rich nutraceutical, with carbamazepine in rats. Toxicology and Applied Pharmacology 2012; 263: 315-22.

26. Garg SK, Kumar N, Bhargava VK and Prabhakar SK: Effect of grapefruit juice on carbamazepine bioavailability in patients with epilepsy. Clinical Pharmacology and Therapeutics 1998; 64: 286-88.

27. Lefebvre T, Foster BC, Drouin CE, Krantis A, Livesey JF and Jordan SA: In-vitro activity of commercial valerian root extracts against human cytochrome P450 3A4. Journal of Pharmacy and Pharmaceutical Sciences 2004; 7: 26573.
28. Sparreboom A, Cox MC, Acharya MR and Figg WD: Herbal remedies in the United States: Potential adverse interactions with anticancer agents. Journal of Clinical Oncology 2004; 22: 2489-03.

29. Zhou S, Gao Y, Jiang W, Huang M, Xu A and Paxton JW: Interactions of herbs with cytochrome P450. Drug Metabolism Reviews 2003; 35: 35-98.

30. Donovan JL, DeVane CL, Chavin KD, Wang JS, Gibson BB, Gefroh HA and Markowitz JS: Multiple night-time doses of valerian (Valeriana officinalis) had minimal effects on CYP3A4 activity and no effect on CYP2D6 activity in healthy volunteers. Drug Metabolism and Disposition 2004; 32: 1333-36.

31. Gurley BJ, Gardner SF, Hubbard MA, Williams DK, Gentry WB, Khan IA and Shah A: In-vivo effects of goldenseal, kava kava, black cohosh, and valerian on human cytochrome P450 1A2, 2D6, 2E1, and 3A4/5 phenotypes. Clinical Pharmacology and Therapeutics 2005; 77: 415-26

32. Riviere JE: Comparative Pharmacokinetics: Principles, techniques and applications. John Wiley \& Sons Publisher, second edition 2007.

33. Koumaravelou K, Adithan C, Shashindran CH, Asad M and Abraham BK: Effect of honey on carbamazepine kinetics in rabbits. Indian Journal of Experimental Biology 2002; 40: 560-63.

How to cite this article:

Abushammala I: The effect of valerian on the pharmacokinetics of carbamazepine in healthy rabbits. Int J Pharm Sci \& Res 2014; 5(9): 3641-45. doi: 10.13040/IJPSR.0975-8232.5(9).3641-45.

All @ 2013 are reserved by International Journal of Pharmaceutical Sciences and Research. This Journal licensed under a Creative Commons Attribution-NonCommercial-ShareAlike 3.0 Unported License.

This article can be downloaded to ANDROID OS based mobile. Scan QR Code using Code/Bar Scanner from your mobile. (Scanners are available on Google Playstore) 